\title{
The test study of iron ion migration characteristics on pollution laterite
}

\author{
Peng Liu ${ }^{1}$, Ying Huang, ${ }^{2}$ * \\ ${ }^{1}$ The Oxbridge College Kunming University of science and technology, Kun Ming, China \\ ${ }^{2}$ The Power Engineering Academy Kunming University of Science and Technology, Kun Ming, China
}

\section{Email address:}

liupeng611@163.com (Peng Liu), huangying3764@sina.com.cn (Ying Huang)

\section{To cite this article:}

Peng Liu, Ying Huang. The Test Study of Iron Ion Migration Characteristics on Pollution Laterite. Earth Sciences.

Vol. 3, No. 6, 2014, pp. 132-136. doi: 10.11648/j.earth.20140306.11

\begin{abstract}
The environmental geotechnical problems seriously affect the safety of geotechnical structure and the sustainable development of ecology. The pollution of laterite which is widely used in the infrastructure construction in Yunnan has been a grave threat to the safety of the laterite structure and groundwater as a result of the environmental problems. According to the proposed test plan for typical laterite and six ferric sulfate hydrate, different compaction work was prepared under different temperature, different moisture content and pollution for compaction sample of laterite, the concentration change of iron ion was analyzed over time, and characteristics of iron ions about the laterite migration change has been clear. The results of migrating, from the features of migrating change about iron ions, presents: at the same moment, with smaller compaction, higher moisture content, and the higher temperature, the migrating of iron ion in laterite is much faster, the concentration of iron ions is higher in the solution; at different moment, with time prolonged, it increases gradually, and it gradually reduces in the laterite. The research results will offer a theoretical foundation to the prevention and remedy of the laterite pollution in Yunnan, and will be very important in solving the problem of pollution caused by the discharge of pollutants. The results will also provide theoretical guide and technological support for the sustainable development of Yunnan economy and ecology as well as for the future laboratory experiments.
\end{abstract}

Keywords: Element Fe, Migration Characteristics, Migration Test, Transportation Regularity, Pollution Laterite

\section{Introduction}

The environmental geotechnical problems seriously affect the safety of geotechnical structure and the sustainable development of ecology. The pollution of laterite which is widely used in the infrastructure construction in Yunnan has been a grave threat to the safety of the laterite structure and groundwater as a result of the environmental problems. With the economic development, the discharges of solid waste are continuously increasing in our country. Although measly solid waste can be utilized, the massive solid waste piled up using ways discharge of wet method. This discharge ways can occupancy substantive soil, as well as expend substantive water resources and cause pollution of soil and water for the pollution in solid waste gradualness infiltrate to the soil and water by eluviation. The more and more pollution came from departmental pollution and the pollution level went over severity of the both with urbanize tenor and industrial economy. Expulsion the virulence and deleterious pollution will be influence the surrounding environment. The familiar differential element with: $\mathrm{Fe} 、 \mathrm{~N} 、 \mathrm{Cl} 、 \mathrm{P} 、 \mathrm{Ca} 、 \mathrm{Hg} 、 \mathrm{As}$ 、 $\mathrm{Pb} 、 \mathrm{Cr} 、 \mathrm{U} 、 \mathrm{Cd} 、 \mathrm{Mn}$ and so on (Shabnam Gholamifarda et al. 2008; Jiazuo Zhou et al. 2012). Pollution into the Yunnan laterite can change the soil engineering properties.

The pollution stacked on the soil to do in favor of influence towards stack regional soil. Take a wide view near few decades, the study procure some important production about the chemical weathering of the camp tailings, the heavy metal elementary exoneration and enrichment, the biotic environment geochemistry effect and the toxic element to camp environment relation in soil. The study established theoretical basis for more examined in depth for later generations (Markus Bauer et al. 2008; Liu Peng et al. 2011; Liu Peng et al. 2010). Yet seldom scholar considers the influence of pollution transportation for the Yunnan laterite. This article makes a study of the pollution of the Yunnan 
laterite transportation regularity and takes $\mathrm{Fe}$ element as the research object.

\section{The Test Material and Process}

\subsection{Properties of Test Materials}

Pollutant selected join preparation pollution samples in soil, will pollute the sample immersion in the solution, the concentration of pollutants in the test solution for study the variation characteristics of pollutant migration. (Shen Jingwen et al. 2009; Abdelmalek Bouazzaa et al. 2007; LuQ et al. 2007). Test of Kunming typical laterite, first of all to the chemical components in soil were determined, to confirm the source of pollutants, in order to simulate the natural state migration of pollutants under the better in the groundwater. Typically, the contents of various chemical compositions of Kunming typical laterite in Table2-1 and Table 2-2.

The table shows:

(1) the main component of laterite for silica, alumina and ferric oxide, stable compounds, for steady chemical Compound, which also contains a small amount free material, when the basic concentration lower than the state regulations will not cause pollution to groundwater.

(2) a few heavy metals in the soil and the poisonous and harmful trace elements content, and most of the poisonous and harmful trace elements in the compound form, it is difficult to directly cause pollution of groundwater.

Therefore, the main source of contamination of groundwater contamination is from stockpiling in edaphic pollutant. When the pollutant in the poisonous and harmful trace elements by leaching of rainfall will enter into the soil, in various forms of infiltration into the groundwater, the final pollution of groundwater. The correctness is verified by the test of polluted soil test.

This test selected iron ions as pollution elements, selecting six hydrated ferric sulfate solution to carry out the test for pollutants.

Table 2-1. The properties of laterite

\begin{tabular}{|c|c|c|c|c|c|c|c|c|c|}
\hline \multicolumn{5}{|c|}{ Bound water } & \multirow[b]{2}{*}{$\begin{array}{l}\text { relative } \\
\text { density }\end{array}$} & \multicolumn{4}{|c|}{ Particle composition (\%) } \\
\hline $\begin{array}{l}\text { natural } \\
\text { moisture } \\
\text { content }(\%)\end{array}$ & $\begin{array}{l}\text { Plastic limit } \\
(\%)\end{array}$ & $\begin{array}{l}\text { Liquid limit } \\
(\%)\end{array}$ & $\begin{array}{l}\text { Plastic limit } \\
\text { index }\end{array}$ & $\begin{array}{l}\text { Liquid limit } \\
\text { index }\end{array}$ & & $\begin{array}{l}2-1 \\
\mathrm{~mm}\end{array}$ & $\begin{array}{l}1-0.075 \\
\mathrm{~mm}\end{array}$ & $\begin{array}{l}\text { 0.075-0.005 } \\
\mathrm{mm}\end{array}$ & $\begin{array}{l}\leq 0.005 \\
\mathrm{~mm}\end{array}$ \\
\hline 23.3 & 28.1 & 48.3 & 20.2 & 1.24 & 2.79 & 4.2 & 10.3 & 40.3 & 45.2 \\
\hline
\end{tabular}

Table 2-2. The chemical composition of laterite

\begin{tabular}{llllllllll}
\hline Chemical composition & $\mathrm{SiO}_{2}$ & $\mathrm{Al}_{2} \mathbf{O}_{3}$ & $\mathbf{F e}_{2} \mathbf{O}_{3}$ & $\mathbf{K}_{2} \mathbf{O}$ & $\mathbf{N a}_{2} \mathbf{O}$ & $\mathbf{C a O}$ & $\mathbf{P}_{2} \mathbf{O}_{5}$ & $\mathbf{M g O}$ & $\mathbf{O}$ thers \\
\hline Content $(\%)$ & 38.43 & 31.52 & 26.78 & 1.62 & 0.54 & 0.52 & 0.13 & 0.08 & 0.38 \\
\hline
\end{tabular}

\subsection{Develop of Test Plan}

The iron ion concentration changes depending on the laterite for internal characteristics and external factors under the condition of water environment.

The inherent characteristics of laterite samples including compactness, its moisture content and iron ion concentration in laterite, external factors mainly refer to the influence of environment temperature and the soaking time, the result of both internal and external causes determines the migration process of laterite iron ion, iron ion concentration caused by changes in water solution. Therefore, in order to analysis the influence of different factors on migration of iron ion in the experiment of laterite, considering the compaction work, moisture content, temperature and soaking time on the four factors, the study of iron ions in clay sample transfer to concentration in aqueous solution.

Many factors affect the migration of pollutants in the groundwater, in the lab are hard to simulate the control of many factors, such as soil interception, biological sink function and so on, but also some of the factors that can be controlled, such as soil compaction, soil moisture content, temperature, etc. This experiment mainly considering soil compaction work, soil moisture and temperature effects for the concentration of iron ion. To add a certain concentration in
Kunming typical laterite in six hydrated ferric sulfate into compacted samples, using standard compression ring knife soaking sample directly in the compacted samples, by certain conditions of soaking finally took the solution containing iron ions to determine the concentration of the iron ion. The experiment was divided into three schemes.

(1) Keep a water and soil temperature ratio unchanged, the migration of the impact of pollutants control soil different compactive effort to study soil compaction work.

(2) Keep the temperature and soil compaction work unchanged, migration affects water to study soil water control of different soil pollutants.

(3) Keep the soil moisture content and compaction work unchanged, to study the effect of temperature on the transport of pollutants control in different temperature.

\subsection{Preparation the Sample}

Experiment preparation process is as follows: the experiment of soil take Yunnan laterite, according to the requirements of the experiments, make sure that the water ratio of the soil, go again to infiltrate the soil of distilled water to join the concentration is $2 \%$ Fe solution $\left(\mathrm{Fe}_{2}\left(\mathrm{SO}_{4}\right)_{3} \cdot 6 \mathrm{H}_{2} \mathrm{O}\right)$, the purpose is prepare the contaminative laterite, made the handles by compaction experiment. 
Soak samples preparation process is as follows:

(1) Sampling: After the completion of the compaction, compaction samples from using standard compression cutting ring (high for $2 \mathrm{~cm}$, for $30 \mathrm{~cm}$ in diameter) sampling.

(2) Wrapped samples: Remove the standard compression cutting ring, and wrapped the samples with medical gauze.

(3) Soak: Place the samples in a $400 \mathrm{~mL}$ beaker of distilled water. Will a beaker along with samples in the thermo tank together, finished the sample preparation.

Extraction of Fe Solution

According to the experimenting program, intervals of 1 hour extracted from the beaker Fe solution $300 \mathrm{~mL}$, into sealed baggie.

At the same time the sample to soak in a $400 \mathrm{~mL}$ beaker of distilled water, continue to experiment, wait until 1 hour after the Fe solution will beaker extracted into sealed baggie, and again with the sample in $400 \mathrm{~mL}$ of distilled water, apart until each sample bathed three hours, remove the intervals of 1 hour of Fe solution.

Experiment Concentration of Fe Solution

The concentration of $\mathrm{Fe}$ solution was detected by the spectrophotometer method when scented to the laboratory.

\section{Analysis of Test Results}

\subsection{Effect of Compaction Work on Iron Ion Concentration}

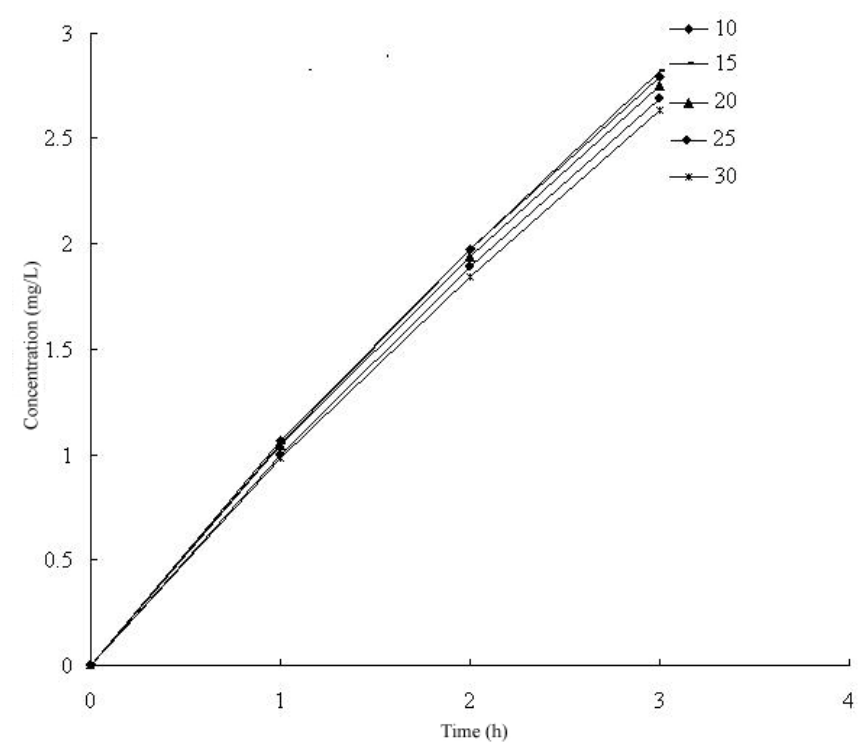

Fig 3.1. The concentration change of the differ compaction work for $\mathrm{Fe}$ $\left(m g \cdot L^{-1}\right)$

Figure 3.1 shows the total change trend of iron ion migration concentration in the pollutant for the different compaction work when the temperature is $22.5{ }^{\circ} \mathrm{C}$ and water content of soil is $22.57 \%$. .Analysis table and the graph are not hard to find:

(1) At the same time, along with compaction work up, the concentration of iron ion decreases, describing slower migrating of iron ion in the laterite.

(2) At the same compaction work level, if prolonged time, the concentration of iron ion decreases gradually, showing the gradual reduction of iron ion concentration in laterite.

\subsection{Effect of Water Content on Iron Ion Concentration}

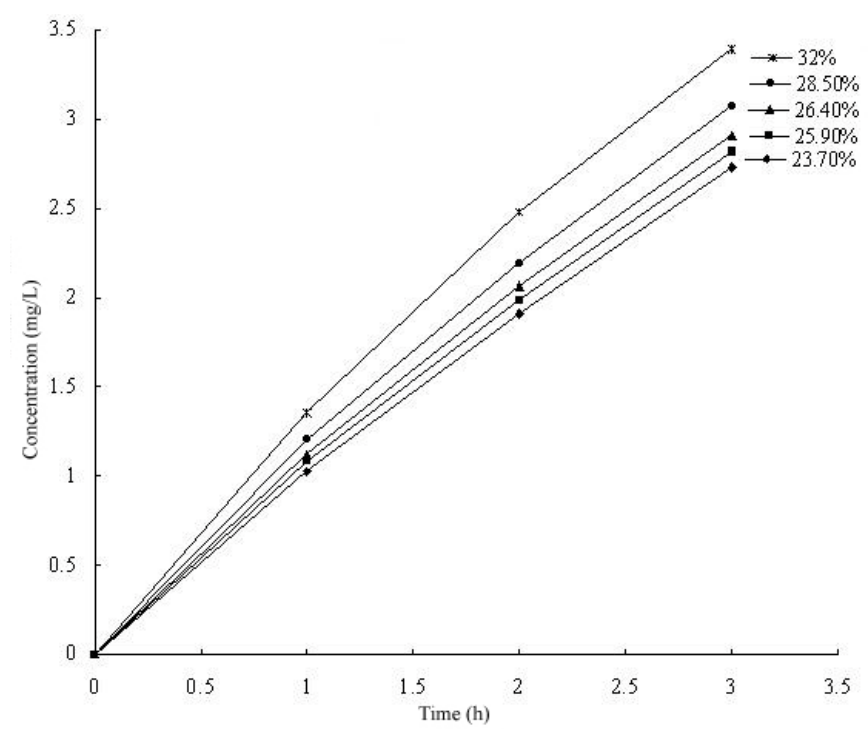

Fig 3.2. The concentration change of the differ water content for $\mathrm{Fe}\left(\mathrm{mg} \cdot \mathrm{L}^{-1}\right)$

Figure 3.2 shows the total change trend of iron ion migration concentration in the pollutant for the moisture content in different conditions when the compaction of 1 soil works 15 for each layer and the temperature is $22.5{ }^{\circ} \mathrm{C}$. Analysis table and the graph is not hard to find:

(1) At the same time, along with water content up, the concentration of iron ion increases, describing faster migrating of iron ion in the laterite.

(2) At the same water content level, if prolonged time, the concentration of iron ion increases gradually, showing the gradual reduction of iron ion concentration in laterite

\subsection{Effect of Temperature on Iron Ion Concentration}

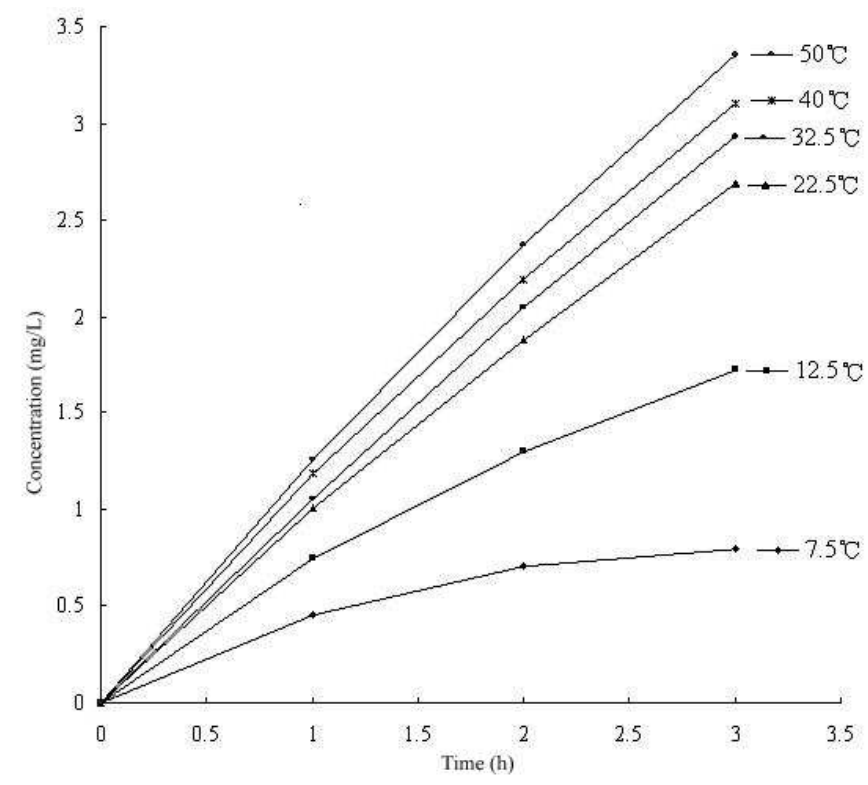

Fig 3.3. The concentration change of the differ temperature for $\mathrm{Fe}\left(m g \cdot L^{-1}\right)$ 
Figure 3.3 shows the total change trend of iron ion migration concentration in the pollutant for the different temperature when the compaction of 1 soil works 15 for each layer and water content of soil is $22.57 \%$. .Analysis table and the graph is not hard to find:

(1) At the same time, along with temperature up, the concentration of iron ion increases, describing faster migrating of iron ion in the laterite.

(2) At the same temperature level, if prolonged time, the concentration of iron ion increases gradually, showing the gradual reduction of iron ion concentration in laterite.

\subsection{Characteristics of Migration Change about Iron Ions in Laterite}

To sum up, features of the concentration change of iron ion can be easily found out from the above test results:

(1) At the same moment, the smaller is the compaction, the greater is the moisture content; the higher the temperature, the faster migrating of iron ion in the laterite and the higher iron ion concentration.

(2) At the different moment, with time prolonged, the concentration of iron ions is gradually increasing, and iron ions concentration in laterite gradually reduces.

\subsection{Characteristics of Transport in Laterite of Fe}

In a word, the concentration changes characteristics can be discovered from the experiment results in $\mathrm{Fe}$ as follows:

(1) The solution of Fe concentration increase gradually and the transport of $\mathrm{Fe}$ in laterite faster along with the increase of moisture content and decrease of compaction power at the same time.

(2) The solution of Fe concentration increase gradually and the concentration of $\mathrm{Fe}$ in laterite decrease with the increase of the time, at the same compaction power and the moisture content.

Immersion test showed that containing iron oxide red soil samples after soaked, caused by the concentration of aqueous solution of iron ions increases, indicating the occurrence of iron ions in clay migration, the migration process is also affected by the compaction work, moisture content, temperature and the soaking time, the change of the concentration of iron ion in water solution properties indirectly reflects the laterite iron ion migration characteristics and migration ability. Obviously, the concentration of iron ion in water solution is higher, reflecting the migration ability of clay samples of iron ion in the stronger. Therefore, in order to clay migration to their onion change in aqueous solution as the foundation, we can study the migration characteristics and migration mechanism of water environment conditions of laterite iron ions in depth, and provide scientific basis for the mechanism of occurrence and development of geological disasters in the laterite region revealed.

The test can forecast of quantitative pollution and the situation on the regional hydrogeology material can effectively puts forward the prevention and control of pollution control measures, for effective and scientific management pollution discharge area of the ecological environment problems bring has important theoretical and practical significance.

\section{Conclusion}

(1) According to the proposed test plan for typical laterite and six ferric sulfate hydrate, different compaction work was prepared under different temperature, different moisture content and pollution for compaction sample of laterite, the concentration change of iron ion was analyzed over time, and characteristics of iron ions about the laterite migration change has been clear.

(2) At the same moment, with the increase of compaction work, the solution of Fe ion concentration decreases, showing slower migrating of iron ion; if worked same compaction, with time prolonged, it is gradually increasing, showing that it gradually decreases.

(3) At the same moment, with the increase of moisture content, it increases, showing its faster migrating; under the same moisture content, with time prolonged, it increases gradually, showing it gradually decreases.

(4) At the same moment, with the increase of temperature, it increases, showing its faster migrating; Under the same temperature, with time prolonged, it increases gradually, showing it gradually decreases.

(5) The results of migrating, from the features of migrating change about iron ions, presents: at the same moment, with smaller compaction, higher moisture content, and the higher temperature, the migrating of iron ion in laterite is much faster, the concentration of iron ions is higher in the solution; at different moment, with time prolonged, it increases gradually, and it gradually reduces in the laterite.

The model can forecast of quantitative pollution and the situation on the regional hydrogeology material can effectively puts forward the prevention and control of pollution control measures, for effective and scientific management pollution discharge area of the ecological environment problems bring has important theoretical and practical significance.

\section{Acknowledgements}

This research was financially supported by the National Science Foundation (51168022) and the scientific research key fund project of Education Department of Yunnan Province (2013Z114).

\section{References}

[1] Shabnam Gholamifarda, Robert Eymardb, Christian Duquennoia. Modeling anaerobic bioreactor landfills in methanogenic phase: Long term and short term behaviors [J]. Water Research, 2008,42: 5061-5071

[2] Jiazuo Zhou, Dongqing Li. Numerical analysis of coupled water, heat and stress in saturated freezing soil $[\mathrm{J}]$. Cold Regions Science and Technology, 2012,72: 43-49 
[3] Markus Bauer, Beate Fulda, Christian Blodau. Groundwater derived arsenic in high carbonate wetland soils: Sources, sinks, and mobility [J]. Science of the Total Environment, 2008,401: $109-120$

[4] Liu Peng, "The Study of Transportation Regularity for Different Element," IEEE Xi' an. China, vol. 4, pp. 3136-3138, May 2011

[5] Liu Peng, "The Study of Transportation Regularity Consider Temperature," IEEE ChengDu. China, vol. 1, pp. 3-7, May 2010

[6] Shen Jingwen. The proposition of fertilizer pesticide and wastewater irrigation in groundwater. Agricultural Environment Protection, 2009,11(3):137-139

[7] Abdelmalek Bouazzaa, Stephan Jefferis, Thaveesak
Vangpaisal. Investigation of the effects and degree of calcium exchange on the Atterberg limits and swelling of geosynthetic clay liners when subjected to wet-dry cycles [J]. Geotextiles and Geomembranes, 2007,25: 170-185

[8] Lu Q, He Z L L, Graetz D A, Stoffella R J, Yang X E. Phytoremediation to remove nutrients and improve entropic storm waters using water lettuce [J]. Envimnmenial Science and Pollution Research, 2010,17: 84-96

[9] Peng Zezhou, Yang Tianhang. Aquatic environment mathematical model and application [M]. Beijing: chemical engineering industry press, 2007, 1(1):5-94

[10] Kirzhner F, Zimmels Y, Malkovskaja A, Starosvetsky J. Removal of microbial biofilm on Water Hyacinth plants roots by ultrasonic treatment [J]. Ultrasonics, 2009,49: 153-158 